\title{
Effects of Bushen-Yizhi formula on age-related inflammation and oxidative stress in senescence-accelerated mice
}

\author{
XUE-QIN HOU ${ }^{1 *}$, HOU-PAN SONG ${ }^{2 *}$, YUN-BO CHEN $^{3}$, SHU-YI CHENG ${ }^{3}$, \\ SHU-HUAN FANG ${ }^{3}$, JI-GUO ZHANG ${ }^{1}$ and QI WANG $^{3}$ \\ ${ }^{1}$ Institute of Pharmacology, Taishan Medical College, Tai'an, Shandong 271016; \\ ${ }^{2}$ Hunan Provincial Key Laboratory of Diagnostics in Chinese Medicine, Hunan University of \\ Chinese Medicine, Changsha, Hunan 410208; ${ }^{3}$ Design, Measurement and Evaluation in Clinical Research Center, \\ Institute of Clinical Pharmacology, Guangzhou University of Chinese Medicine, Guangzhou, Guangdong 510405, P.R. China
}

Received July 8, 2016; Accepted April 27, 2017

\section{DOI: $10.3892 / \mathrm{mmr} .2018 .8736$}

\begin{abstract}
The present study aimed to investigate the possible effects and underlying molecular mechanism of Bushen-Yizhi formula (BSYZ), a traditional Chinese medicine, on age-related degeneration of brain physiology in senescence-accelerated mouse prone 8 (SAMP8) mice. SAMP8 mice (age, 6 months) were administered BSYZ (1.46, 2.92 and $5.84 \mathrm{~g} / \mathrm{kg} /$ day) for 30 days. Morris water maze and step-down tests demonstrated that BSYZ significantly improved memory impairments in SAMP8 mice. In addition, BSYZ significantly enhanced the expression levels of peroxisome proliferator-activated receptor- $\gamma$ and B-cell lymphoma extra-large, and downregulated the expression levels of inflammatory mediators, glial fibrillary acidic protein, cyclooxygenase- 2 , nuclear factor- $\kappa \mathrm{B}$ and interleukin- $1 \beta$ in the brain compared with untreated SAMP8 mice. Furthermore, BSYZ reversed disordered superoxide dismutase activity, malondialdehyde content and glutathione peroxidase activity, and ameliorated apoptosis and histological alterations. The present study indicated that BSYZ may attenuate cognitive impairment in SAMP8 mice, and modulate inflammation, oxidative stress and neuronal apoptosis. These results suggested that BSYZ may have the potential to be further developed into a therapeutic agent for protection against age-related neurodegenerative diseases.
\end{abstract}

Correspondence to: Professor Ji-Guo Zhang, Institute of Pharmacology, Taishan Medical College, 619 Chang Cheng Road, Tai'an, Shandong 271016, P.R. China

E-mail: jiguotsmc@163.com

Professor Qi Wang, Design, Measurement and Evaluation in Clinical Research Center, Institute of Clinical Pharmacology, Guangzhou University of Chinese Medicine, 12 Airport Road, Guangzhou, Guangdong 510405, P.R. China

E-mail: wangqi@gzucm.edu.cn

${ }^{*}$ Contributed equally

Key words: Bushen-Yizhi formula, aging, cognitive impairment, inflammation, oxidative stress, neuronal apoptosis

\section{Introduction}

Age-related brain health decline is an important risk factor for neurodegenerative diseases, including Alzheimer's disease (AD) and Parkinson's disease (PD), which are characterized by cognitive impairment, behavioral alterations and motor dysfunction. Inflammation contributes to cognitive decline, and abnormalities in brain structure and metabolism (1). Astrocytes serve an important role in modulating inflammation of the central nervous system. Astrocytosis in the brain may be an early phenomenon in $\mathrm{AD}$ development $(2,3)$, and increased expression of glial fibrillary acidic protein (GFAP) by astrocytes has been reported to be associated with an AD-like pathology $(4,5)$. Reactive astrocytes surrounding senile plaques may be responsible for the ongoing inflammatory process in AD via the release of cytokines and other toxic products (6), including interleukin (IL)-1ß $(7,8)$ and IL-6 (9). Cyclooxygenase (COX)-2 is a rate-limiting enzyme involved in the production of prostaglandins, which is also involved in inflammatory mechanisms. The increase of neuronal COX-2 signaling in the hippocampus may be an indicator of dementia progression in early AD (10). Furthermore, the activation of COX-2 may be induced by IL- $1 \beta$ and other cytokines $(11,12)$. These inflammatory mediators may finally activate the nuclear factor (NF)- $\mathrm{kB}$ signaling pathway (13). Conversely, agonists of peroxisome proliferator-activated receptor (PPAR)- $\gamma$ reduced COX-2 protein expression, NF- $\mathrm{KB}$ activation and oxidative stress (14).

Previous studies have suggested that oxidative stress is a prominent feature in patients with mild cognitive impairment (MCI) and AD (15-17), which exhibit high levels of the product of lipid peroxidation [malondialdehyde (MDA)] and low activities of antioxidants [superoxide dismutase (SOD) and glutathione peroxidase (GSH-Px)]. In addition, oxidative stress is associated with the development of neuronal death and neural dysfunction in $\mathrm{AD}$ and $\mathrm{PD}$, which are two common age-related neurodegenerative diseases (18). In addition, patients with PD exhibited higher levels of inflammatory markers compared with control individuals $(19,20)$. Therefore, inhibiting inflammation and oxidative stress may be an important strategy for the treatment of age-related neurodegenerative diseases. 
Bushen-Yizhi formula (BSYZ) is a Chinese medical compound, which acts via numerous mechanisms. Our previous studies have demonstrated that BSYZ may attenuate cognitive impairment in AD-like animal models, and affect the modulation of numerous targets $(21,22)$. The present study aimed to investigate the effects of BSYZ on learning and memory abilities in senescence-accelerated mouse prone 8 (SAMP8) mice, and examined the underlying molecular mechanisms involved in age-related alterations, including inflammation, oxidative stress and neuronal apoptosis, in the brains of mice.

\section{Materials and methods}

Preparation of BSYZ extracts. BSYZ extracts were provided by the School of Chinese Materia Medica, Guangzhou University of Chinese Medicine (Guangzhou, China), as described previously (22). The doses of BSYZ extracts were expressed as the weight of original raw herbs in grams per kilogram of body weight.

Animals and housing. Male SAMP8 mice (age, 3 months; weight, $35 \pm 5 \mathrm{~g} ; \mathrm{n}=48$ ), and age-matched senescence-accelerated mouse resistant 1 (SAMR1) mice (weight, $35 \pm 5 \mathrm{~g}$; $\mathrm{n}=12$ ) were purchased from the Animal Research Center of Peking University (Beijing, China). All mice were housed at the Experimental Animal Center of Guangzhou University of Chinese Medicine under a controlled temperature $\left(20 \pm 2^{\circ} \mathrm{C}\right)$, a relative humidity of $55 \pm 2 \%$ and a 12 -h light/dark cycle with ad libitum access to food and water. Experimental protocols were approved by the Animal Ethics Committee of Guangzhou University of Chinese Medicine, and experiments were performed in compliance with the Guide for the Care and Use of Laboratory Animals (https:/grants.nih.gov/grants/olaw/guidefor-the-care-and-use-of-laboratory-animals.pdf).

Drug administration. SAMP8 mice were randomly divided into four groups: SAMP8 (vehicle, saline only; $n=12$ ), L-BSYZ (low dose BSYZ, 1.46 g/kg/day; n=10), M-BSYZ (middle dose BSYZ, $2.92 \mathrm{~g} / \mathrm{kg} /$ day; $\mathrm{n}=10$ ) and H-BSYZ (high dose BSYZ, $5.84 \mathrm{~g} / \mathrm{kg} /$ day; $\mathrm{n}=9$ ). SAMR1 mice served as a healthy control and were treated with saline $(n=12)$. At the age of 6 months, when the SAMP8 mice show impaired memory (23), all mice received drug or saline by oral administration once daily for 30 days.

Behavioral tests. After 30 days of drug administration, mice were acclimated to the environment of the behavioral test room for 3 days. Morris water maze test and step-down test were performed to investigate the learning and memory abilities of mice.

Morris water maze test. The equipment for the Morris water maze test consisted of a black circular pool (diameter, $120 \mathrm{~cm}$; height, $40 \mathrm{~cm}$ ) and a camera monitor linked to video-tracking software Behavior Sys (Guangzhou Feidi Biological Technology Co., Ltd., Guangzhou, China). The test was performed as described by Chen et al (24) with minor modifications. Briefly, the test consisted of two phases: Hidden-platform training and spatial probe trial. During hidden-platform training, the platform (diameter, $8 \mathrm{~cm}$ ) was located in one of four equal quadrants of the pool and submerged $1 \mathrm{~cm}$ below the surface of the water. The water was $30 \mathrm{~cm}$ in depth, $22-26^{\circ} \mathrm{C}$ and made opaque with non-toxic white paint. Mice were given four trials a day (120 sec each) for 5 days. The time to find the platform (the escape latency) was recorded. If the mouse failed to find the platform within $120 \mathrm{sec}$, the escape latency was recorded as $120 \mathrm{sec}$, and the mouse was directed to the platform. Mice were allowed to stay on the platform for $20 \mathrm{sec}$ after finding or being guided to the platform. At the end of the daily trial, mice were dried and returned to their home cages. On the sixth day, memory was assessed via a spatial probe trial where the platform was removed. Each mouse was given only one trial for $120 \mathrm{sec}$ from the starting point opposite to the platform location. The number of mice crossing the previous platform position and time spent in the target quadrant were recorded.

Step-down test. The apparatus for the step-down test consisted of a plastic testing box $(12 \times 12 \times 18 \mathrm{~cm})$ and a rubber platform placed in a corner of the box (Guangzhou Feidi Biological Technology Co., Ltd.). The step-down test was conducted as described by Zhu et al (25). The number of errors and the latency were recorded using video tracking software (Guangzhou Feidi Biological Technology Co. Ltd. China) to measure memory learning and retention.

Brain sections and tissue preparation. Following performance of the behavioral tests, 3 mice per group were used for preparation of brain sections, according to a previously described protocol (22). Brain coronal sections were taken for immunohistochemistry and histological examination. The remaining mice were anesthetized (sodium pentobarbital, $50 \mathrm{mg} / \mathrm{kg}$ body weight) and decapitated; the brains were rapidly removed, divided into two parts (the hippocampus and cortex) on ice and stored at $-80^{\circ} \mathrm{C}$. The cortexes and hippocampi were used for biochemical analysis and reverse transcription-quantitative polymerase chain reaction (RT-qPCR), respectively.

Immunohistochemistry. Immunohistochemical staining was performed as previously described (22). The following primary antibodies were used: GFAP (SC-9065; 1:200; Santa Cruz Biotechnology, Inc., Dallas, TX, USA), COX-2 (12282; 1:200; Cell Signaling Technology, Inc.), PPAR- $\gamma$ (2435; 1:200; Cell Signaling Technology, Inc.), NF-кB (6956; 1:200; Cell Signaling Technology, Inc.) and B-cell lymphoma extra-large (Bcl-xL; 2764; 1:200, Cell Signaling Technology, Inc.). Following incubation with primary antibodies at $4^{\circ} \mathrm{C}$ overnight, sections were washed in $0.1 \mathrm{M}$ phosphate buffered saline (PBS) and incubated with anti-rabbit or anti-mouse horseradish peroxidase linked secondary antibodies (7074 or 7076; 1:2,000; Cell Signaling Technology, Inc.) for $1 \mathrm{~h}$ at $37^{\circ} \mathrm{C}$. Following washing in PBS, sections were incubated with diaminobenzidine (PA110; Tiangen Biotech Co., Ltd., Beijing, China), and counterstaining with hemalum (AR0005; Boster Biological Technology, Pleasanton, CA, USA). Photomicrographic images were captured using a Leica DM4000B microscope (Leica Microsystems, Inc., Wetzlar, Germany) and Leica QWin plus version 4 software (Leica Microsystems, Inc.). For semi-quantitative analysis, the percentage of the positively stained area was measured at 
original magnification x200 using Leica QWin plus software (Leica Microsystems, Inc.).

Histological examination. Terminal deoxynucleotidyl transferase dUTP nick-end labeling (TUNEL) staining, hematoxylin and eosin $(\mathrm{H} \& \mathrm{E})$ and Nissl staining were performed according to the manufacturer's protocol of the following kits: FragEL ${ }^{\mathrm{TM}}$ DNA Fragmentation Detection kit (QIA33; Merck KGaA, Darmstadt, Germany), Hematoxylin-Eosin kit (AR1180; Wuhan Boster Biological Technology, Ltd., Wuhan, China), and Nissl staining solution (C0117; Beyotime Institute of Biotechnology, Haimen, China). Images were captured using a Leica DM4000B microscope and Leica QWin plus software (Leica Microsystems, Inc.).

Biochemical analysis. To determine MDA content, SOD and GSH-Px activities, the cortexes of mice were homogenized with $0.9 \%$ saline $(10 \mathrm{ml} / \mathrm{g}$ sample weight) on ice and centrifuged at $3,000 \mathrm{x} \mathrm{g}$ for $10 \mathrm{~min}$ at $4^{\circ} \mathrm{C}$. The supernatant was used for analysis according to the kits protocols (A003-1, A001-1-1 and A005 for MDA, SOD and GSH-Px, respectively; Nanjing Jiancheng Bioengineering Institute, Nanjing, China,). Absorbance (532, 550 and $420 \mathrm{~nm}$ wavelength for MDA, SOD and GSH-Px, respectively) was measured using a universal microplate spectrophotometer (Bio-Rad Laboratories, Inc., Hercules, CA, USA).

RT-qPCR. Mice hippocampi were homogenized with RNAiso Plus (D9108A; Takara Biotechnology Co., Ltd., Dalian, China) and total RNA was extracted according to the manufacturer's protocols. After quantifying total RNA with a NanoDrop 2000 spectrophotometer (NanoDrop; Thermo Fisher Scientific, Inc., Wilmington, ME, USA), reverse transcription was performed using the PrimeScript ${ }^{\mathrm{TM}}$ RT Master Mix (Perfect Real Time; RR036A; Takara Biotechnology Co., Ltd.) according to the manufacturer's protocol. Cycling conditions were as follows: $37^{\circ} \mathrm{C}$ for $15 \mathrm{~min}, 85^{\circ} \mathrm{C}$ for $5 \mathrm{sec}$ and $4^{\circ} \mathrm{C}$. Amplification reactions were performed in a total reaction volume of $25 \mu \mathrm{l}$ using the SYBR ${ }^{\circledR}$ Premix Ex Taq ${ }^{\mathrm{TM}}$ II (Tli RNaseH Plus; RR820A; Takara Biotechnology Co., Ltd.) on a CFX96 ${ }^{\mathrm{TM}}$ Real-Time PCR Detection system (Bio-Rad Laboratories, Inc.). Cycling conditions were as follows: An initial predenaturation step at $95^{\circ} \mathrm{C}$ for $30 \mathrm{sec}$, followed by 40 cycles at $95^{\circ} \mathrm{C}$ for $5 \mathrm{sec}$ and $62^{\circ} \mathrm{C}$ for $30 \mathrm{sec}$, then $95^{\circ} \mathrm{C}$ for $10 \mathrm{sec}$, melt curve step at 65 to $95^{\circ} \mathrm{C}$ (increments $0.5^{\circ} \mathrm{C}$, each for $5 \mathrm{sec}$ ). Each sample was analyzed in triplicate. Primers were designed and synthesized by Thermo Fisher Scientific, Inc. (Waltham, MA, USA). Primer sequences were as follows: IL-1 $\beta$ (ILIB), forward 5'-GAAATG CCACCTTTTGACAGTG-3', reverse 5'-TGGATGCTCTCA TCAGGACAG-3'; IL-6 (IL6), forward 5'-TCTATACCACTT CACAAGTCGGA-3', reverse 5'-GAATTGCCATTGCAC AACTCTTT-3'; and $\beta$-actin, forward 5'-GGCTGTATTCCC CTCCATCG-3' and reverse 5'-CCAGTTGGTAACAATGCC ATGT-3'. $\beta$-actin was used as housekeeping gene. The relative amount of target gene expression was normalized against housekeeping gene and calculated by the $2^{-\Delta \Delta \mathrm{Cq}}$ method (26).

Statistical analysis. SPSS version 17.0 software (SPSS, Inc., Chicago, IL, USA) was used for statistical analysis. Differences in escape latency in the Morris water maze test were analyzed by a repeated measures analysis of variance, whereas the remaining data was analyzed by one-way analysis of variance or a nonparametric test (Kruskal-Wallis test) where appropriate. Data are expressed as the mean \pm standard error (experiments were repeated at least three times, except the behavioral tests). The least significant difference post hoc test was used to establish significance between individual groups. $\mathrm{P}<0.05$ was considered to indicate a statistically significant difference.

\section{Results}

Effects of BSYZ on learning and memory of SAMP8 mice in the Morris water maze test. Spatial learning and memory in the SAMP8 mice was determined using the Morris water maze test. In the hidden-platform training phase, there were significant differences in escape latency between the groups ( $\mathrm{F}=4.612, \mathrm{P}=0.003)$; however, there no significant difference was observed among training days $(\mathrm{F}=0.164, \mathrm{P}=0.957)$ or in the interactive effect between group and training day $(\mathrm{F}=1.549, \mathrm{P}=0.086)$. Post hoc analysis revealed that the escape latency in the SAMP8 group was significantly greater than the SAMR1 group (day 1-2, $\mathrm{P}<0.05$; day 3-5, $\mathrm{P}<0.01$ ). Following treatment with low dose BSYZ, the escape latency on day 5 was significantly reduced compared with the SAMP8 group $(\mathrm{P}<0.05)$. No significant difference in escape latency was observed between the M-BSYZ/H-BSYZ and SAMP8 groups (Fig. 1A).

In the spatial probe trial phase, there were significant differences in the times crossing the platform location (Kruskal-Wallis Test: $\left.\chi^{2}=21.706, \mathrm{P}<0.001\right)$ and the time spent in the target quadrant $(\mathrm{F}=2.879, \mathrm{P}=0.032)$ among the groups. The time crossing the platform in the SAMP8 group was significantly reduced compared with the SAMR1 group $(\mathrm{P}<0.01$; Fig. 1B). A similar result was observed for time spent in the target quadrant between SAMP8 and SAMR1 groups $(\mathrm{P}<0.01$; Fig. 1C). Compared with the SAMP8 mice, in the L-BSYZ treatment group, the time spent in the target quadrant was significantly increased (Fig. $1 \mathrm{C} ; \mathrm{P}<0.05$ ); however, the time crossing the platform between these two groups was not significantly different (Fig. 1B).

Effects of BSYZ on learning and memory of SAMP8 mice in the step-down test. Another method of assessing learning is measuring passive avoidance using a step-down test. There were significant differences in the number of errors made among the groups $(\mathrm{F}=3.313, \mathrm{P}=0.018)$. The number of errors in the SAMP8 group was significantly increased compared with the SAMR1 group ( $\mathrm{P}<0.01$; Fig. $2 \mathrm{~A})$. Compared with the SAMP8 group, administration of BSYZ at low and middle doses significantly reduced the number of errors $(\mathrm{P}<0.05$; Fig. 2A). No significant difference was observed in latency between the groups $(\mathrm{F}=2.185, \mathrm{P}=0.085$; Fig. $2 \mathrm{~B})$.

Effects of BSYZ on GFAP expression in the brains of SAMP 8 mice. Immunohistochemical staining of GFAP was performed in brain sections from the mice (Fig. 3A). There were significant differences in GFAP expression in the hippocampus $(\mathrm{F}=62.220, \mathrm{P}<0.001)$ and cortex $(\mathrm{F}=3.724$, $\mathrm{P}=0.042$ ) among the groups. GFAP expression in the SAMP8 
A

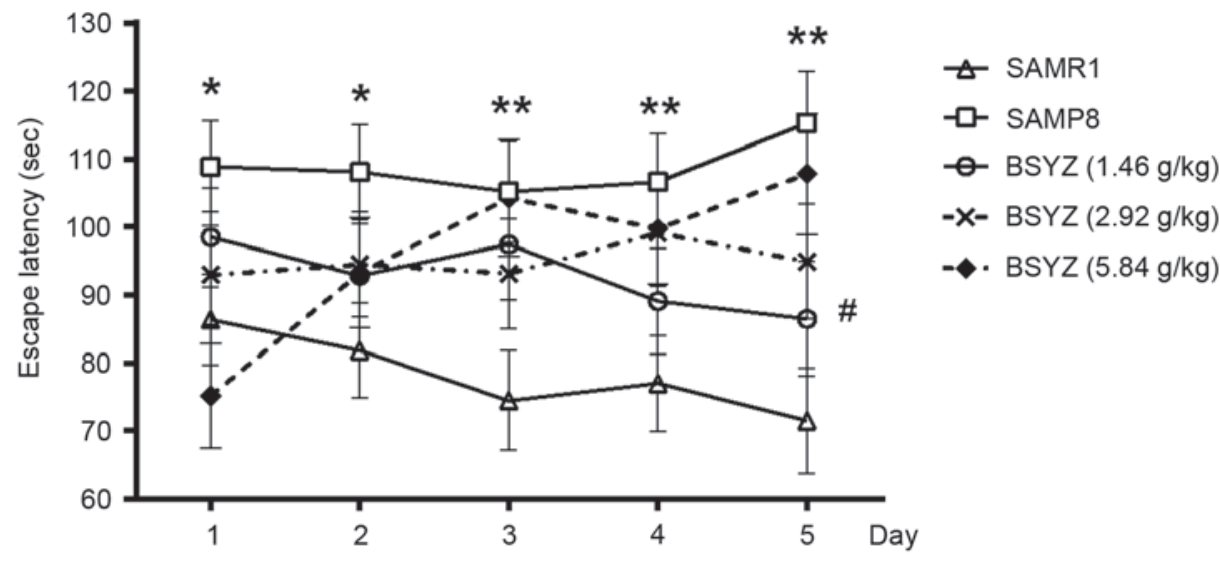

B

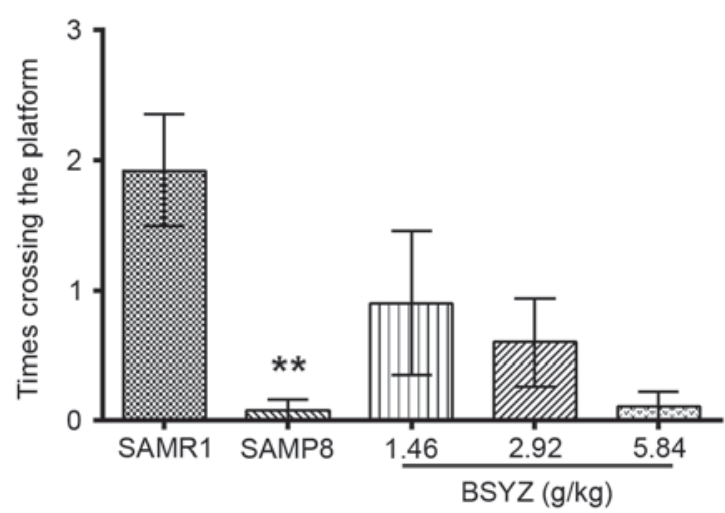

C

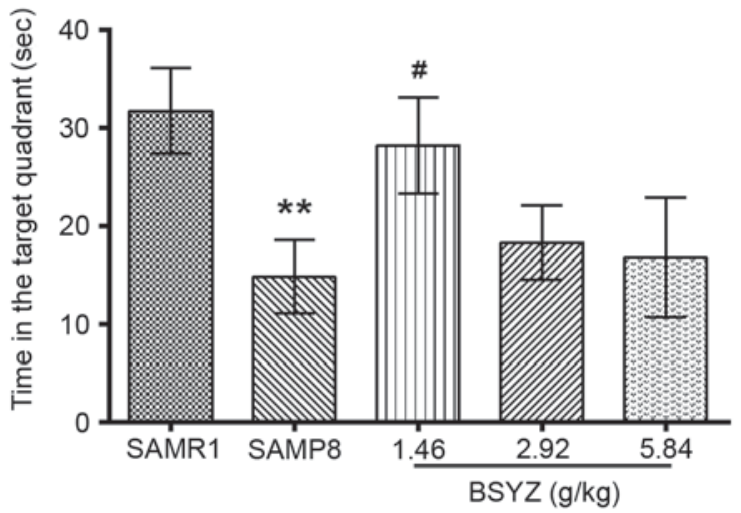

Figure 1. Effects of BSYZ on the Morris water maze test. (A) Escape latency to find the platform in the hidden-platform training test. (B) Time crossing the platform and (C) time spent in the target quadrant in the probe trial in SAMRI, SAMP8, low dose BSYZ $(1.46 \mathrm{~g} / \mathrm{kg})$, medium dose BSYZ (2.92 g/kg) and high dose BSYZ $(5.84 \mathrm{~g} / \mathrm{kg}$ ) mice. Data are presented as the mean \pm standard error (SAMR1, n=12; SAMP8, n=12; L-BSYZ, n=10; M-BSYZ, n=10; H-BSYZ, n=9). ${ }^{*} \mathrm{P}<0.05$ and ${ }^{* *} \mathrm{P}<0.01$ vs. SAMR1 group; ${ }^{*} \mathrm{P}<0.05$ vs. SAMP8 group. BSYZ, Bushen-Yizhi formula; SAMP8, senescence-accelerated mouse prone 8; SAMRI, senescence-accelerated mouse resistant 1 .

A

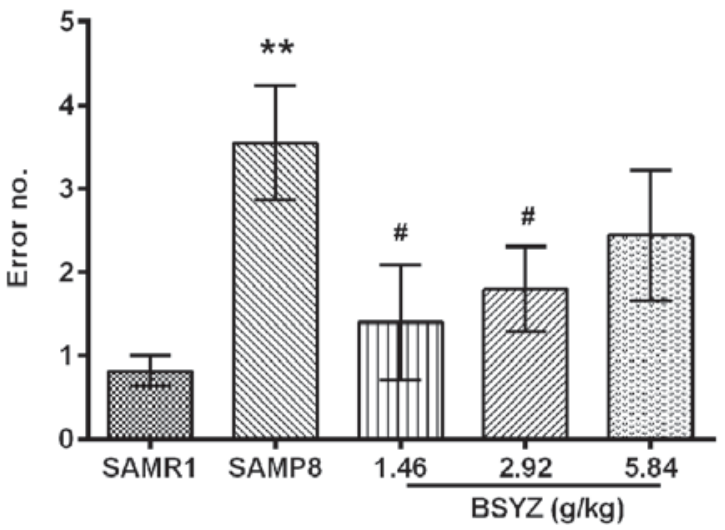

B



Figure 2. Effects of BSYZ on the step-down test. (A) Number of errors and (B) latency in SAMRI, SAMP8, low dose BSYZ (1.46 g/kg), medium dose BSYZ $(2.92 \mathrm{~g} / \mathrm{kg})$ and high dose BSYZ $(5.84 \mathrm{~g} / \mathrm{kg})$ mice. Data are presented as the mean \pm standard error (SAMR1, n=11; SAMP8, n=11; L-BSYZ, n=10; M-BSYZ; $\mathrm{n}=10, \mathrm{H}-\mathrm{BSYZ}, \mathrm{n}=9) .{ }^{* *} \mathrm{P}<0.01$ vs. SAMR1 group; ${ }^{\mathrm{P}} \mathrm{P}<0.05$ vs. SAMP8 group. BSYZ, Bushen-Yizhi formula; SAMP8, senescence-accelerated mouse prone 8; SAMRI, senescence-accelerated mouse resistant 1.

group was significantly increased in the hippocampus and cortex compared with the SAMR1 group $(\mathrm{P}<0.01$; Fig. 3B). BSYZ treatment significantly reduced GFAP expression in the brain compared with the SAMP8 group (hippocampus: All $\mathrm{P}<0.01$; cortex: $\mathrm{P}<0.05$ for $\mathrm{L}-\mathrm{BSYZ}$ and M-BSYZ groups; Fig. 3B).
Effects of BSYZ on COX-2 expression in brains of SAMP8 mice. Immunohistochemical staining of COX-2 was performed in brain sections from the mice (Fig. 4A). There were significant differences in COX-2 expression in the hippocampus $(\mathrm{F}=4.413, \mathrm{P}=0.026)$ and cortex $(\mathrm{F}=14.490, \mathrm{P}<0.001)$ among the groups. COX-2-positive staining in the SAMP8 
A



B

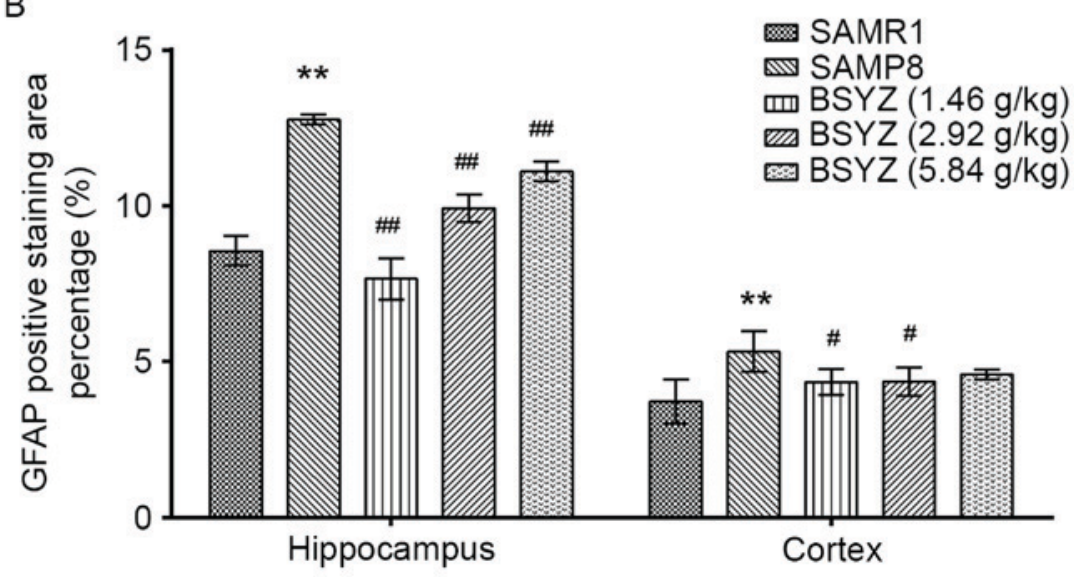

Figure 3. Effects of BSYZ on GFAP expression in brain tissue, as demonstrated by immunohistochemistry. (A) Images of the immunohistochemical staining for GFAP in cortex, DG, CA3 and CA1 tissues of SAMRI, SAMP8, low dose BSYZ (1.46 g/kg), medium dose BSYZ (2.92 g/kg) and high dose BSYZ $(5.84 \mathrm{~g} / \mathrm{kg})$ mice. Scale bar, $30 \mu \mathrm{m}$. (B) Percentage of positively stained GFAP cells. Data are presented as the mean \pm standard error $(\mathrm{n}=3 / \mathrm{group}) .{ }^{* *} \mathrm{P}<0.01$ vs. SAMR1 group; ${ }^{\#} \mathrm{P}<0.05$ and ${ }^{\#} \mathrm{P}<0.01$ vs. SAMP8 group. BSYZ, Bushen-Yizhi formula; SAMP8, senescence-accelerated mouse prone 8; SAMRI, senescence-accelerated mouse resistant; GFAP, glial fibrillary acidic protein; DG, dentate gyrus.

group was significantly enhanced in the hippocampus and cortex compared with the SAMR1 group $(\mathrm{P}<0.05$ and $\mathrm{P}<0.01$, respectively; Fig. 4B). Following treatment with BSYZ, COX-2 expression was significantly decreased in the brain compared with in the SAMP8 group (hippocampus: $\mathrm{P}<0.01, \mathrm{P}<0.05$ and $\mathrm{P}<0.05$ for L-BSYZ, M-BSYZ and H-BSYZ groups, respectively; cortex: All $\mathrm{P}<0.01$; Fig. 4B).

Effects of BSYZ on PPAR- $\gamma$ expression in brains of SAMP8 mice. Immunohistochemical staining of PPAR- $\gamma$ was performed in brain sections from the mice (Fig. 5A). No significant differences in PPAR- $\gamma$ expression were observed in the hippocampus $(\mathrm{F}=1.911, \mathrm{P}=0.185)$; however, there was a significant difference in cortex expression $(\mathrm{F}=6.004, \mathrm{P}=0.010)$ among the groups. PPAR $-\gamma$ expression in the SAMP8 group was significantly reduced in the cortex compared with the SAMR1 group $(\mathrm{P}<0.01$; Fig. 5B). BSYZ treatment significantly increased PPAR- $\gamma$ expression in the cortex compared with the SAMP8 group $(\mathrm{P}<0.01, \mathrm{P}<0.05$ and $\mathrm{P}<0.05$ for $\mathrm{L}-\mathrm{BSYZ}$, M-BSYZ and H-BSYZ groups, respectively; Fig. 5B).
Effects of BSYZ on $N F-\kappa B$ expression in brains of SAMP8 mice. Immunohistochemical staining of $\mathrm{NF}-\kappa \mathrm{B}$ was performed in brain sections from the mice (Fig. 6A). No significant differences in NF- $\kappa \mathrm{B}$ expression were observed in the hippocampus $(\mathrm{F}=2.471, \mathrm{P}=0.112)$; however, there was a significant difference in cortex expression $(\mathrm{F}=31.556, \mathrm{P}<0.001)$ among the groups. $\mathrm{NF}-\kappa \mathrm{B}$ expression in the SAMP8 group was significantly increased in the hippocampus and in the cortex compared with the SAMR1 group $(\mathrm{P}<0.05$ and $\mathrm{P}<0.01$, respectively; Fig. $6 \mathrm{~B})$. However, BSYZ treatment significantly decreased NF- $\kappa$ B expression in the cortex compared with the SAMP8 group $(\mathrm{P}<0.01$ for all BSYZ groups; Fig. 6B).

Effects of BSYZ on ILIB and IL6 mRNA expression in brains of SAMP8 mice. The mRNA expression levels of genes encoding the inflammatory cytokines IL-1 $\beta$ and IL-6, ILIB and IL6, were measured by RT-qPCR. There was a significant difference in $I L 1 B$ mRNA expression levels among the groups $(\mathrm{F}=4.892$, $\mathrm{P}=0.011)$. The expression levels of $I L 1 B$ in the SAMP8 group were significantly higher compared with the SAMR1 group $(\mathrm{P}<0.05$; 

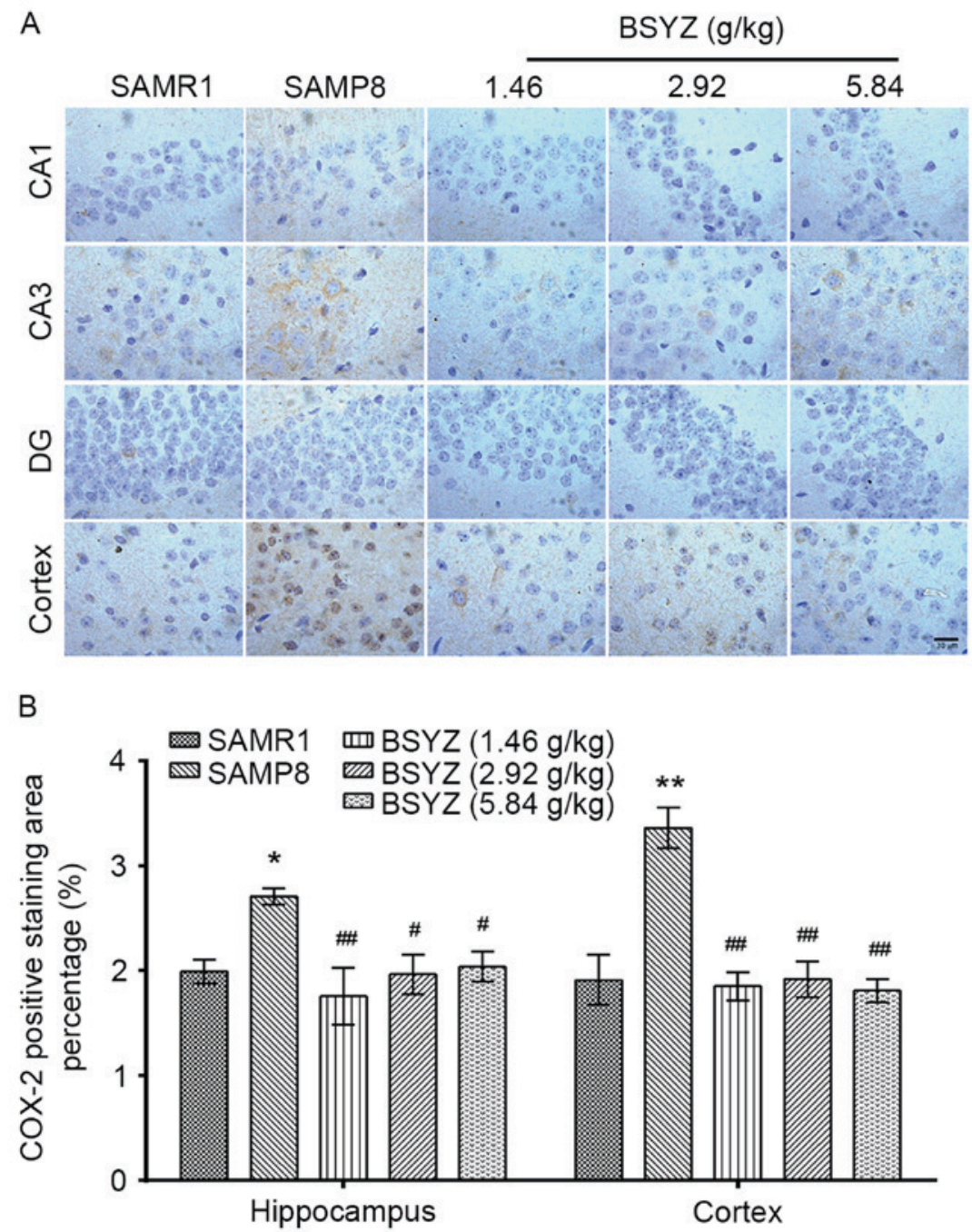

Figure 4. Effects of BSYZ on COX-2 expression in brain tissue, as demonstrated by immunohistochemistry. (A) Images of immunohistochemical staining for COX-2 in cortex, DG, CA3 and CA1 tissues of SAMRI, SAMP8, low dose BSYZ (1.46 g/kg), medium dose BSYZ (2.92 g/kg) and high dose BSYZ $(5.84 \mathrm{~g} / \mathrm{kg}$ ) mice. Scale bar, $30 \mu \mathrm{m}$. (B) Percentage of positively stained COX-2 cells. Data are presented as the mean \pm standard error ( $\mathrm{n}=3 / \mathrm{group}) .{ }^{*} \mathrm{P}<0.05$ and ${ }^{* *} \mathrm{P}<0.01$ vs. SAMR1 group; ${ }^{\mathrm{P}}<0.05$ and ${ }^{\# \#} \mathrm{P}<0.01$ vs. SAMP8 group. BSYZ, Bushen-Yizhi formula; SAMP8, senescence-accelerated mouse prone 8; SAMRI, senescence-accelerated mouse resistant 1; COX-2, cyclooxygenase-2; DG, dentate gyrus.

Fig. 7A). However, BSYZ treatment significantly decreased IL1B expression compared with the SAMP8 group ( $\mathrm{P}<0.01$ for all BSYZ groups; Fig. 7A). No significant difference in IL6 expression was observed among the groups ( $\mathrm{F}=1.994, \mathrm{P}=0.147$; Fig. 7B). However, IL6 was significantly increased in SAMP8 group compared with the SAMR1 group ( $\mathrm{P}<0.05$; Fig. 7B).

Effects of BSYZ on oxidative stress in SAMP8 mice. To assess the effects of BSYZ on oxidative stress of SAMP8 mice, SOD and GSH-Px activities, and MDA content were measured in mice brains (Fig. 8). No significant difference in SOD activity was observed $(\mathrm{F}=1.901, \mathrm{P}=0.163)$; however, there were significant differences in MDA content $(\mathrm{F}=5.458, \mathrm{P}=0.006)$ and $\mathrm{GSH}-\mathrm{Px}$ activity $(\mathrm{F}=5.618, \mathrm{P}=0.006)$ among the groups. Post hoc test demonstrated that MDA content in the SAMP8 group was significantly greater compared with the SAMR1 group $(\mathrm{P}<0.01$; Fig. 8B). Conversely, the activities of SOD and GSH-Px in the SAMP8 mice were significantly reduced compared with the SAMR1 group $(\mathrm{P}<0.05$ and $\mathrm{P}<0.01$, respectively; Fig. $8 \mathrm{~A}$ and $\mathrm{C})$. However, compared with the SAMP8 group, BSYZ treatment significantly reversed SOD activity $(\mathrm{P}<0.05$ in the L-BSYZ group; Fig. 8A), MDA content $(\mathrm{P}<0.01$ for all $\mathrm{BSYZ}$ groups; Fig. 8B) and GSH-Px activity ( $\mathrm{P}<0.01$ for $\mathrm{L}-\mathrm{BSYZ}$ and $\mathrm{P}<0.05$ for M-BSYZ and H-BSYZ groups, respectively; Fig. 8C).

Effects of BSYZ on neuronal apoptosis in brains of SAMP8 mice. The immunohistochemical staining of $\mathrm{Bcl}-\mathrm{xL}$ in the brain tissue sections of mice is presented in Fig. 9A. Significant differences in Bcl-xL expression were observed in the hippocampus $(\mathrm{F}=16.377, \mathrm{P}<0.001)$ and cortex $(\mathrm{F}=110.228, \mathrm{P}<0.001)$ among the groups. Bcl-xL expression in SAMP8 mice was significantly lower compared with the SAMR1 mice (hippocampus, $\mathrm{P}<0.05$; cortex, $\mathrm{P}<0.01$; Fig. 9B). BSYZ treatment significantly increased $\mathrm{Bcl}-\mathrm{xL}$ expression in the hippocampus $(\mathrm{P}<0.05$ for $\mathrm{L}-\mathrm{BSYZ}$ group; Fig. 9B) and cortex $(\mathrm{P}<0.01, \mathrm{P}<0.05$ and $\mathrm{P}<0.05$ for L-BSYZ, M-BSYZ and H-BSYZ groups, respectively; Fig. 9B) compared with the SAMP8 group.

The results of TUNEL staining in the brain tissue sections of mice are presented in Fig. 10. There were significant differences in the number of TUNEL-positive cells in the 
A

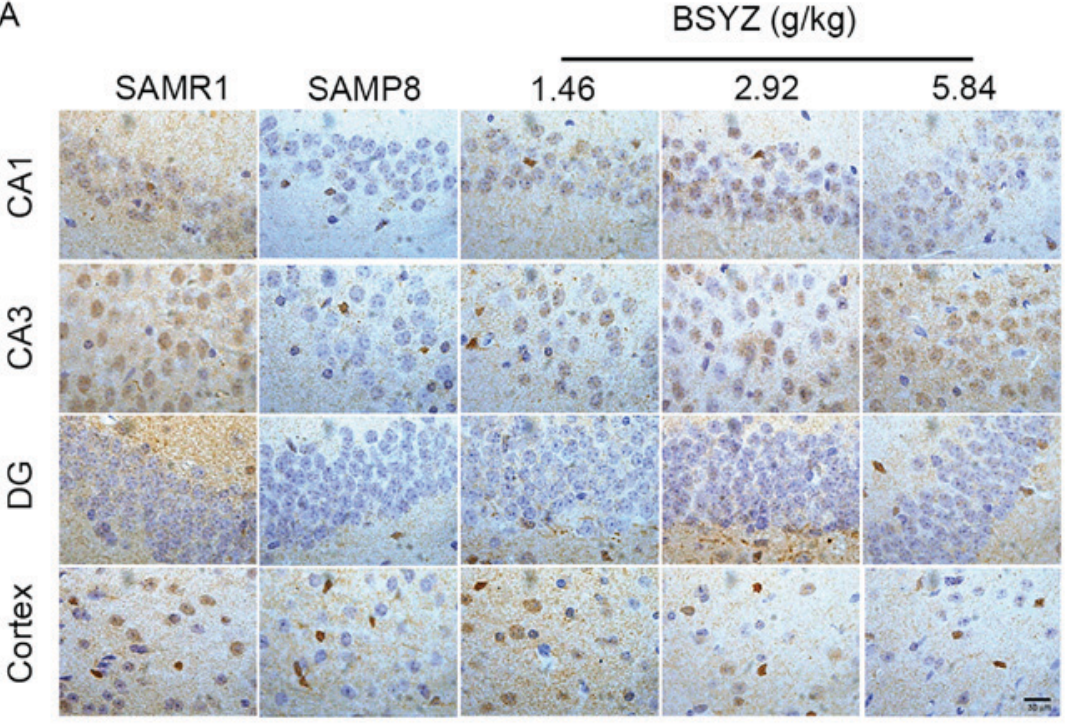

B

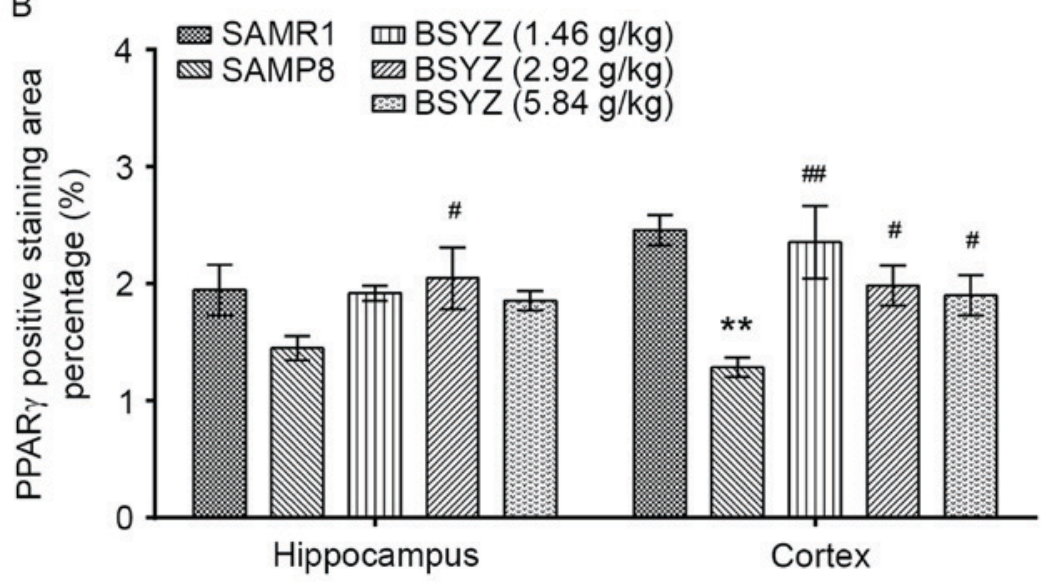

Figure 5. Effects of BSYZ on PPAR- $\gamma$ expression in brain tissue, as demonstrated by immunohistochemistry. (A) Images of the immunohistochemical staining for PPAR $\gamma$ in cortex, DG, CA3 and CA1 tissues of SAMRI, SAMP8, low dose BSYZ (1.46 g/kg), medium dose BSYZ (2.92 g/kg) and high dose BSYZ (5.84 g/kg) mice. Scale bar: $30 \mu \mathrm{m}$. (B) Percentage of positively stained PPAR- $\gamma$ cells. Data are presented as the mean \pm standard error (n=3/group). ${ }^{* *} \mathrm{P}<0.01$ vs. SAMR1 group; ${ }^{*} \mathrm{P}<0.05$ and ${ }^{\# \#} \mathrm{P}<0.01$ vs. SAMP8 group. BSYZ, Bushen-Yizhi formula; SAMP8, senescence-accelerated mouse prone 8; SAMRI, senescence-accelerated mouse resistant 1 ; PPAR- $\gamma$, peroxisome proliferator-activated receptor- $\gamma$; DG, dentate gyrus.

hippocampus $(\mathrm{F}=26.507, \mathrm{P}<0.001)$ and cortex $(\mathrm{F}=20.660$, $\mathrm{P}<0.001)$ among the groups. The number of TUNEL-positive cells in the SAMP8 group was significantly increased compared with the SAMR1 group $(\mathrm{P}<0.01)$. Treatment with BSYZ resulted in a decrease in the number of TUNEL-positive cells in the hippocampus and cortex compared with the SAMP8 group $(\mathrm{P}<0.01)$.

Effects of BSYZ on histological alterations in the brains of SAMP8 mice. As presented in Fig. 11A, irregular arrangement of neurons in the hippocampus and unhealthy neurons (appearing as indistinct, darker or shrunken, lacking a clear cell boundary, and possessing a small darkened nucleus) were observed in brain tissue of SAMP8 mice. There were significant differences in the number of unhealthy neurons in the hippocampus $(\mathrm{F}=24.233, \mathrm{P}<0.001)$ and cortex $(\mathrm{F}=17.947$, $\mathrm{P}<0.001)$ among the groups. In addition, the number of unhealthy neurons in the SAMP8 group was significantly greater than in the SAMR1 group $(\mathrm{P}<0.01$; Fig. 11B). However, administration of BSYZ significantly decreased the number of unhealthy neurons (hippocampus: $\mathrm{P}<0.01, \mathrm{P}<0.01$ and $\mathrm{P}<0.05$ for L-BSYZ, M-BSYZ and H-BSYZ groups, respectively; cortex: $\mathrm{P}<0.01$ for L-BSYZ and M-BSYZ groups; Fig. 11B). Chromatolysis, a decrease in Nissl-stained cells and shrinkage of cells was observed in the brains of SAMP8 mice (Fig. 12A). There were significant differences in the number of Nissl-positive neurons in the hippocampus $(\mathrm{F}=13.428$, $\mathrm{P}<0.001)$ and cortex $(\mathrm{F}=8.273, \mathrm{P}=0.003)$ among the groups. The number of Nissl-positive neurons in the SAMP8 group was significantly reduced compared with the SAMR1 group $(\mathrm{P}<0.01$; Fig. 12B). However, administration of BSYZ significantly increased the number of Nissl-positive neurons (hippocampus: $\mathrm{P}<0.01$ for L-BSYZ group; cortex: $\mathrm{P}<0.05$ for L-BSYZ group; Fig. 12B) compared with the SAMP8 group.

\section{Discussion}

The present study demonstrated that BSYZ treatment exerted a beneficial effect on learning and memory abilities in SAMP8 mice, which was consistent with our previous studies in other 
A



B

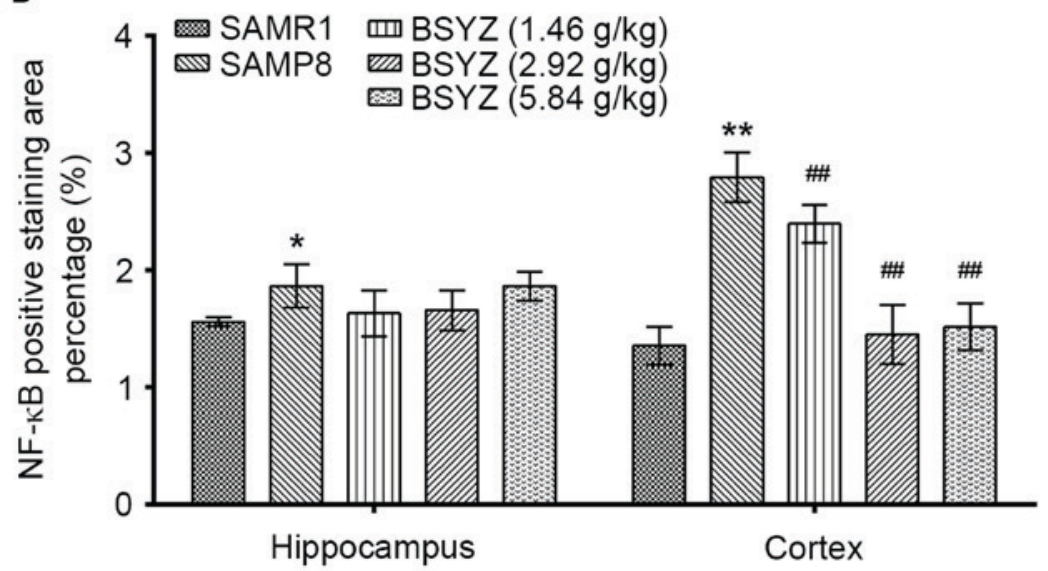

Figure 6. Effects of BSYZ on NF-kB expression in brain tissue, as demonstrated by immunohistochemistry. (A) Images of the immunohistochemical staining for NF-kB in cortex, DG, CA3 and CA1 tissues of SAMRI, SAMP8, low dose BSYZ (1.46 g/kg), medium dose BSYZ (2.92 g/kg) and high dose BSYZ $\left(5.84 \mathrm{~g} / \mathrm{kg}\right.$ ) mice. Scale bar, $30 \mu \mathrm{m}$. (B) Percentage of positively stained NF- $\mathrm{kB}$ cells. Data are presented as the mean \pm standard error (n=3/group). ${ }^{*} \mathrm{P}<0.05$ and ${ }^{* *} \mathrm{P}<0.01$ vs. SAMR1 group; ${ }^{\# *} \mathrm{P}<0.01$ vs. SAMP8 group. BSYZ, Bushen-Yizhi formula; SAMP8, senescence-accelerated mouse prone 8; SAMRI, senescence-accelerated mouse resistant $1 ; \mathrm{NF}-\kappa \mathrm{B}$, nuclear factor- $\mathrm{\kappa} B$; DG, dentate gyrus.
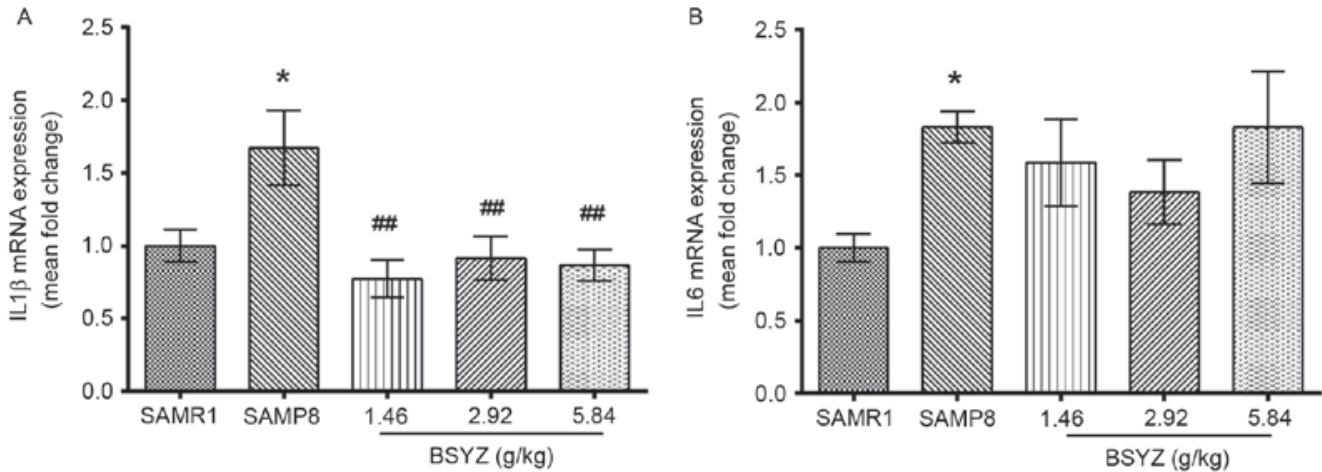

Figure 7. Effects of BSYZ on ILIB and IL6 mRNA expression levels in the hippocampus of mice. (A) ILIB and (B) IL6 expression levels in the hippocampus of SAMRI, SAMP8, low dose BSYZ $(1.46 \mathrm{~g} / \mathrm{kg})$, medium dose BSYZ $(2.92 \mathrm{~g} / \mathrm{kg})$ and high dose BSYZ $(5.84 \mathrm{~g} / \mathrm{kg})$ mice. Data are presented as the mean \pm standard error ( $\mathrm{n}=4$ /group). ${ }^{*} \mathrm{P}<0.05$ vs. SAMR1 group; ${ }^{\# \#} \mathrm{P}<0.01$ vs. SAMP8 group. BSYZ, Bushen-Yizhi formula; SAMP8, senescence-accelerated mouse prone 8; SAMRI, senescence-accelerated mouse resistant 1; IL1B, interleukin-1 $\beta$ gene; IL6, interleukin-6 gene.

AD-like animal models $(21,22)$. In addition, BSYZ treatment demonstrated anti-inflammatory and antioxidative effects, and decreased neuronal apoptosis in SAMP8 mice.
SAMP8 mice harbor AD-like cognitive and behavioral alterations, and a neuropathological phenotype (27). In the present study, SAMP8 mice demonstrated significant 



Figure 8. Effects of BSYZ on SOD, MDA and GSH-Px levels in the cortex of SAMP8 mice. (A) SOD activity, (B) MDA content and (C) GSH-Px activity in the cortex of SAMRI, SAMP8, low dose BSYZ $(1.46 \mathrm{~g} / \mathrm{kg})$, medium dose BSYZ $(2.92 \mathrm{~g} / \mathrm{kg})$ and high dose BSYZ $(5.84 \mathrm{~g} / \mathrm{kg})$ mice. Data are presented as the mean \pm standard error ( $\mathrm{n}=4$ /group). ${ }^{*} \mathrm{P}<0.05$ and ${ }^{* *} \mathrm{P}<0.01$ vs. SAMR1 group; $\mathrm{P}<0.05$ and ${ }^{\# / "} \mathrm{P}<0.01$ vs. SAMP8 group. BSYZ, Bushen-Yizhi formula; SAMP8, senescence-accelerated mouse prone 8; SAMRI, senescence-accelerated mouse resistant 1; SOD, superoxide dismutase; MDA, malondialdehyde; GSH-Px, glutathione peroxidase.
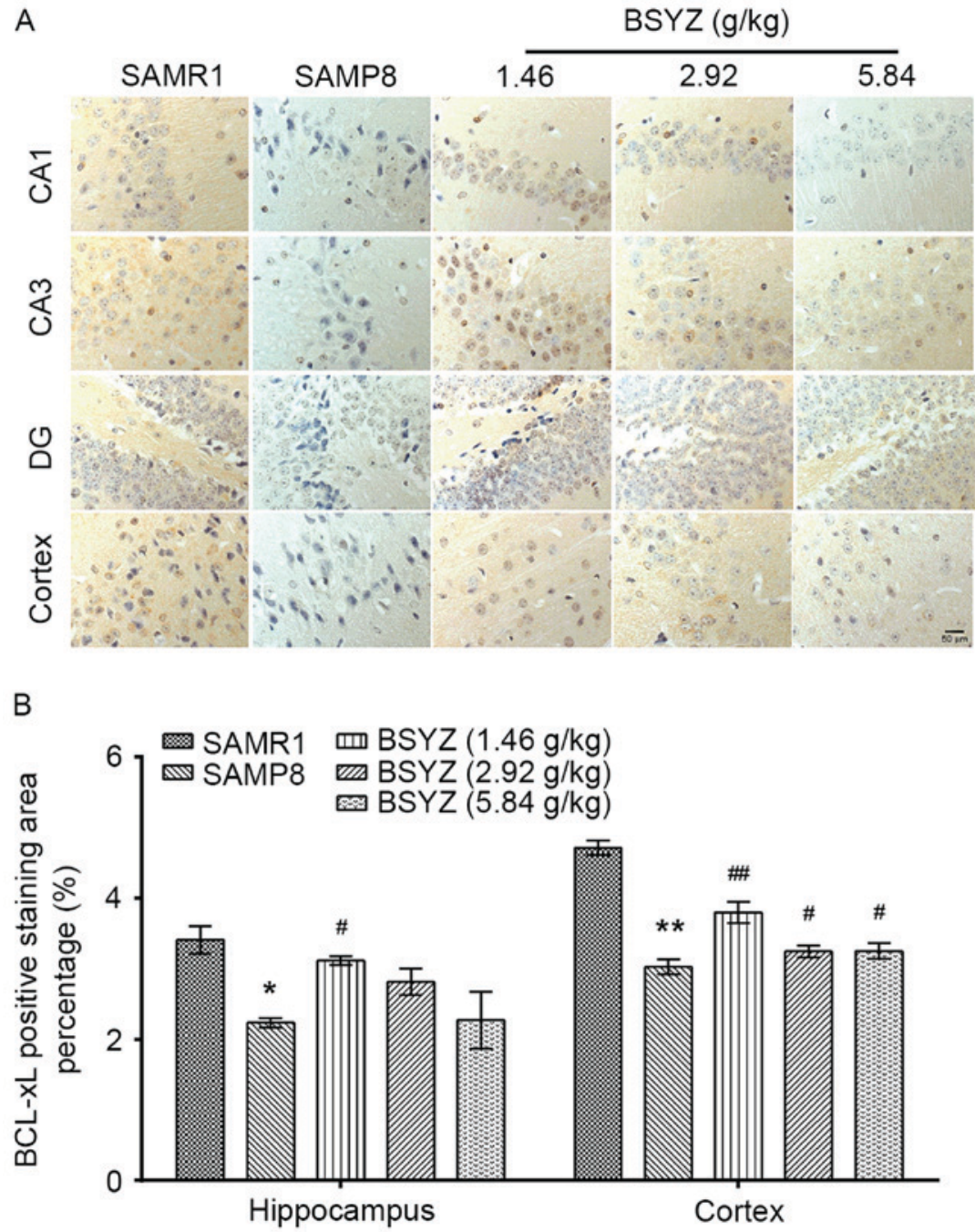

Figure 9. Effects of BSYZ on Bcl-xL expression in brain tissue, as demonstrated by immunohistochemistry. (A) Images of immunohistochemical staining for Bcl-xL in cortex, DG, CA3 and CA1 tissues of SAMRI, SAMP8, low dose BSYZ (1.46 g/kg), medium dose BSYZ (2.92 g/kg) and high dose BSYZ $\left(5.84 \mathrm{~g} / \mathrm{kg}\right.$ ) mice. Scale bar, $50 \mu \mathrm{m}$. (B) Percentage of positively stained Bcl-xL cells. Data are presented as the mean \pm standard error $(\mathrm{n}=3 / \mathrm{group}){ }^{*} \mathrm{P}<0.05$ and ${ }^{* *} \mathrm{P}<0.01$ vs. SAMR1 group; ${ }^{\mathrm{P}}<0.05$ and ${ }^{\# \# ~} \mathrm{P}<0.01$ vs. SAMP8 group. BSYZ, Bushen-Yizhi formula; SAMP8, senescence-accelerated mouse prone 8; SAMRI, senescence-accelerated mouse resistant 1; Bcl-xL, B-cell lymphoma extra-large; DG, dentate gyrus.

impairment of spatial learning and memory in a Morris water maze test, in addition to deficiency of passive avoidance response in a step-down test, compared with SAMR1 mice. These results were similar to other studies $(28,29)$. Furthermore, 
A

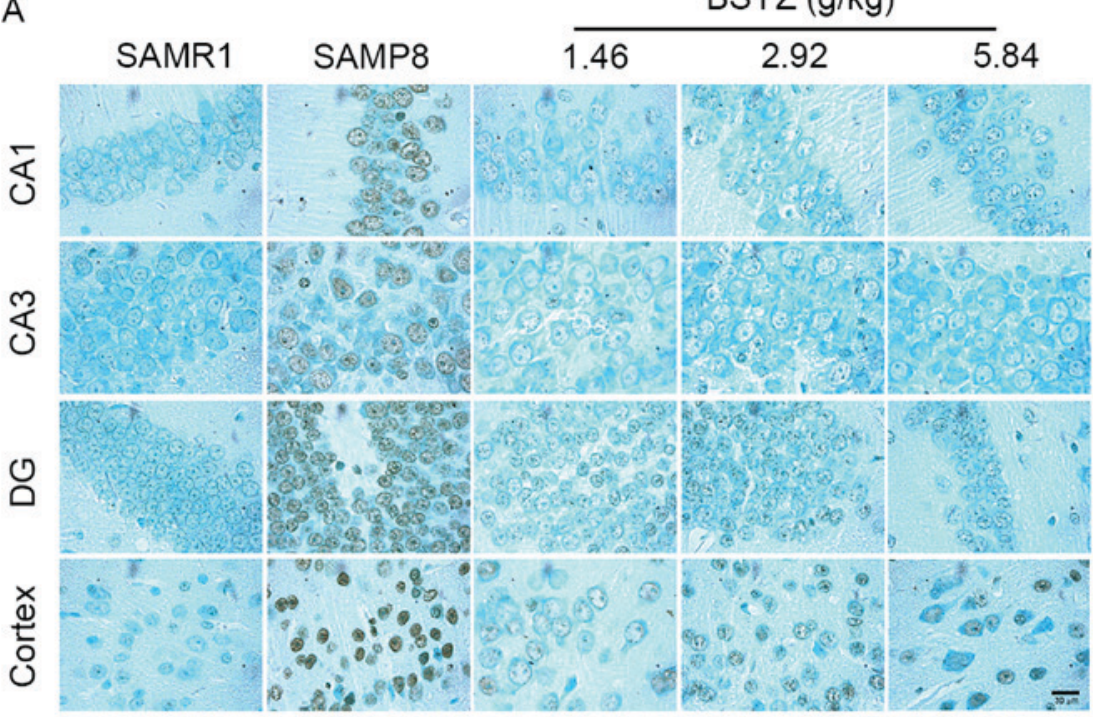

\section{B}

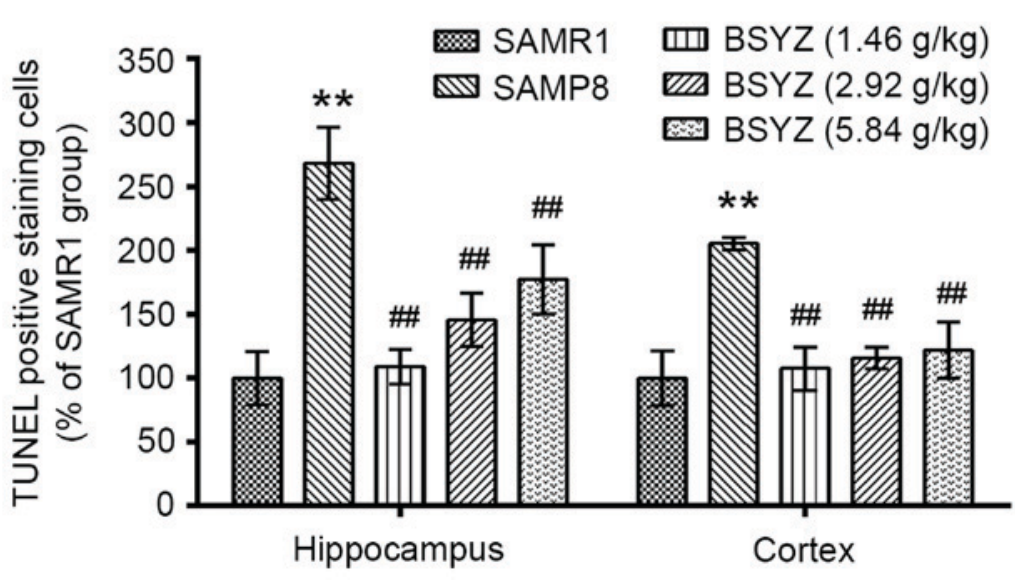

Figure 10. Effects of BSYZ on TUNEL staining of brain tissue. (A) Images of TUNEL staining in cortex, DG, CA3 and CA1 tissues of SAMRI, SAMP8, low dose BSYZ (1.46 g/kg), medium dose BSYZ (2.92 g/kg) and high dose BSYZ (5.84 g/kg) mice. Scale bar, $30 \mu \mathrm{m}$. (B) Percentage of positively stained TUNEL cells. Data are presented as the mean \pm standard error ( $\mathrm{n}=3$ /group). ${ }^{* *} \mathrm{P}<0.01$ vs. SAMR1 group; ${ }^{\# \prime} \mathrm{P}<0.01$ vs. SAMP8 group. BSYZ, Bushen-Yizhi formula; SAMP8, senescence-accelerated mouse prone 8; SAMRI, senescence-accelerated mouse resistant 1; TUNEL, terminal deoxynucleotidyl transferase dUTP nick-end labeling.

administration of BSYZ improved cognitive impairment in SAMP8 mice. Low dose BSYZ exhibited an improved cognition-enhancing effect compared with the higher doses; however, a further dose-effect study is warranted.

Inflammation is a risk factor in the course of neurodegenerative diseases, including dementia. It has been suggested that plasma levels of inflammatory proteins are increased prior to the clinical onset of dementia, AD and vascular dementia (30). Increased peripheral levels of inflammatory markers are also associated with a modest increase in the risk of all types of dementia (31).

Astrocytes are involved in the neuroinflammatory response and become reactive in response to the majority of pathological situations in the brain, including axotomy, ischemia, infection and neurodegenerative diseases (13). Astrocyte reactivity was originally characterized by morphological alterations, including hypertrophy and process remodeling, and the overexpression of the intermediate filament GFAP (13). It has been reported that compared with in non-demented individuals, significantly greater GFAP levels were observed in brain samples from individuals diagnosed with $\mathrm{AD}$, mixed dementia and vascular-mediated dementia (32). In addition, age-related increases in cellular hypertrophy of GFAP-positive cells were observed in 6- and 10-month old SAMP8 mice (33). Another study detected higher levels of GFAP in the brains of SAMP8 mice compared with SAMR1 mice via immunofluorescence staining and western blotting (34). Therefore, the present study detected GFAP expression in brain tissue sections from SAMP8 mice and investigated the effects of BSYZ on astrocyte activation. Consistent with previous reports, hypertrophic astrocytes and increased GFAP expression were observed in SAMP8 mice compared with SAMRI mice, which were reduced following treatment with BSYZ. These findings suggested that the effects of BSYZ on inflammation may be mediated, at least partially, by reducing astrocyte activation in the brain.

Astrocytes host a complex network of signaling pathways, providing an abundance of potential molecular targets (35), including the NF- $\mathrm{KB}$ signaling pathway (13). Following 

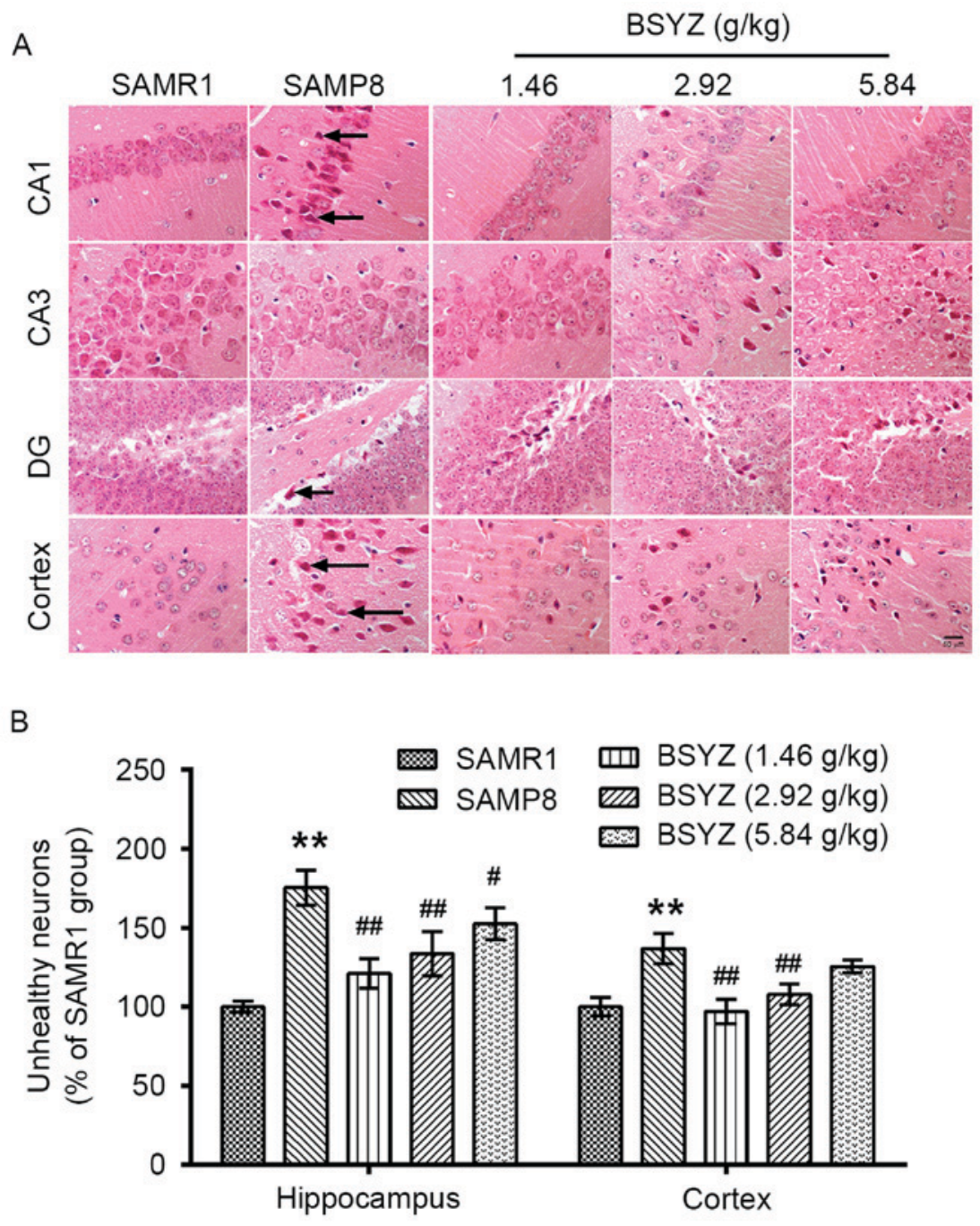

Figure 11. Effects of BSYZ on H\&E staining of brain tissue. (A) Images of H\&E staining in cortex, DG, CA3 and CA1 tissues of SAMRI, SAMP8, low dose BSYZ $(1.46 \mathrm{~g} / \mathrm{kg})$, medium dose BSYZ $(2.92 \mathrm{~g} / \mathrm{kg})$ and high dose BSYZ $(5.84 \mathrm{~g} / \mathrm{kg})$ mice. Black arrows indicate unhealthy neurons. Scale bar: $50 \mu \mathrm{m}$. (B) Percentage of positively stained unhealthy neurons. Data are presented as the mean \pm standard error ( $\mathrm{n}=3 /$ group). ${ }^{* *} \mathrm{P}<0.01$ vs. SAMR1 group; ${ }^{~} \mathrm{P}<0.05$ and ${ }^{\# \#} \mathrm{P}<0.01$ vs. SAMP8 group. BSYZ, Bushen-Yizhi formula; SAMP8, senescence-accelerated mouse prone 8; SAMRI, senescence-accelerated mouse resistant 1; H\&E, hematoxylin and eosin; DG, dentate gyrus.

injection of oligomers of $\beta$-amyloid protein into the cortex of rats, inflammatory markers, including COX-2, IL-1 $\beta$ and TNF- $\alpha$ were expressed in reactive astrocytes, and GFAP and COX-2 proteins co-localized with NF-kB (36). To investigate whether BSYZ had effects on the regulation of inflammatory markers, the present study measured COX-2, NF- $\mathrm{KB}$ and $I L 1 B$ expression in the brain tissue of senescence-accelerated mice. In addition, other inflammatory markers, including IL6 (37) and PPAR- $\gamma,(38)$ which are associated with cognitive function and are used as therapeutic targets, were detected. The results from a previous study suggested that PPAR- $\gamma$ agonists affected modulation of the inflammatory response by reducing COX-2 protein expression and activating MAPKs and NF- $\mathrm{KB}$ in the hippocampus of rats exposed to cerebral ischemia/reperfusion (14). In the present study, the levels of proinflammatory markers in SAMP8 mice were higher than in SAMRI control mice. BSYZ treatment downregulated the expression levels of COX-2 in the hippocampus and cortex of mice, and significantly reduced the NF- $\kappa \mathrm{B}$ expression in the cortex. Conversely, BSYZ significantly increased PPAR- $\gamma$ expression in the cortex compared with untreated SAMP8 rats. In addition, BSYZ treatment significantly downregulated $I L 1 B$; however, no significant differences were observed in the mRNA expression levels of IL6. These results suggested that BSYZ may exert an anti-inflammatory effect by regulating numerous targets. However, further research is required to support this theory.

Alterations in astrocyte function are associated with oxidative stress. It has previously been reported that the expression of certain oxidative stress markers is increased in aged astrocytes (39). Oxidative damage is associated with aging and age-related diseases. In the serum of patients with MCI and $\mathrm{AD}$, the activity of primary enzymatic antioxidant defenses (SOD and GSH-Px) were decreased and production of the MDA lipid peroxidation marker were increased, compared with the age-matched control group (40). Similar alterations in oxidative stress markers were observed in SAMP8 mice (41). Therefore, to assess the effects of BSYZ on oxidative stress, the present study determined the SOD, MDA and GSH-Px levels in the brains of SAMP8 mice. Results revealed that 

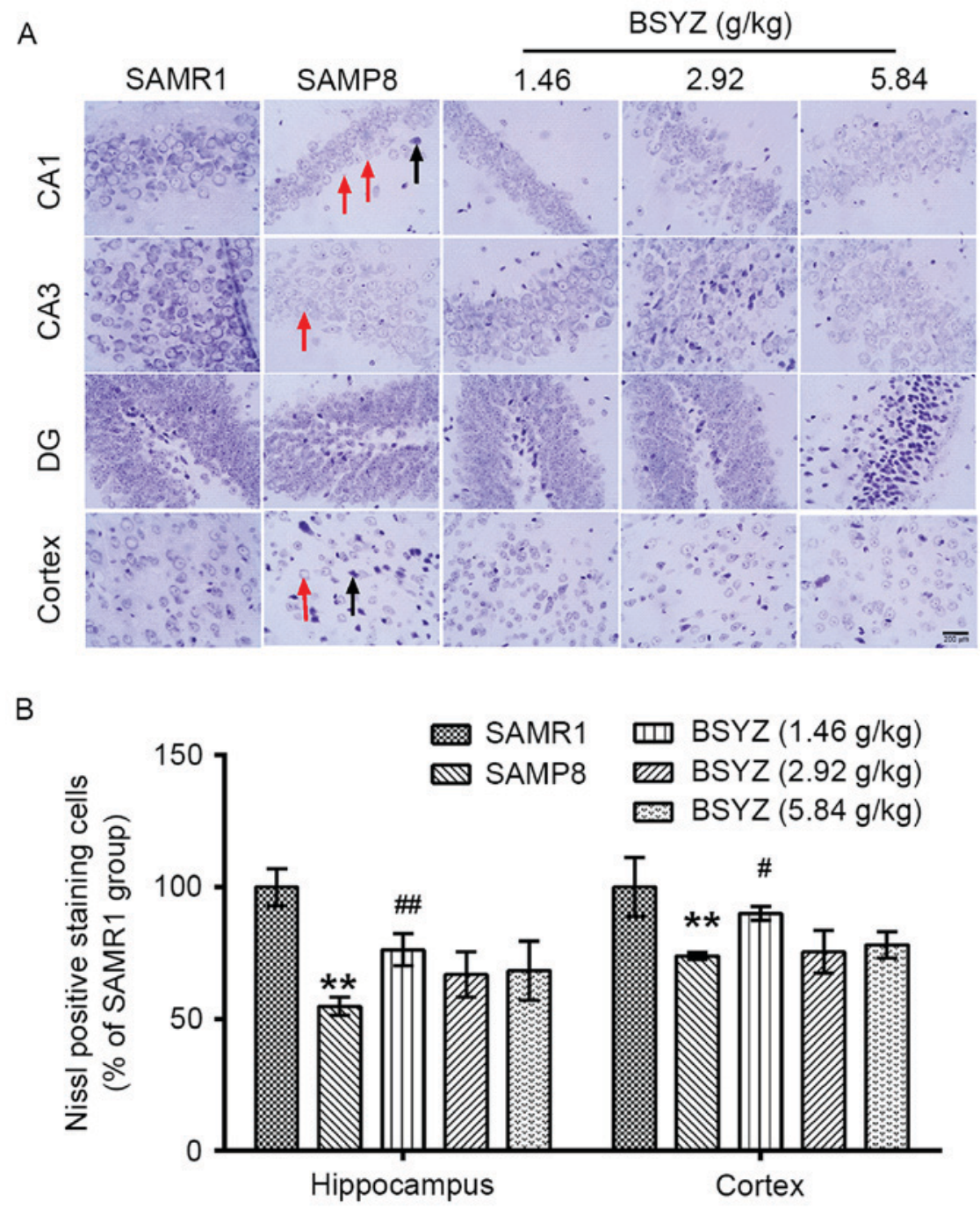

Figure 12. Effects of BSYZ on Nissl staining of brain tissue. (A) Images of Nissl staining in cortex, DG, CA3 and CA1 tissues of SAMRI, SAMP8, low dose BSYZ (1.46 g/kg), medium dose BSYZ (2.92 g/kg) and high dose BSYZ (5.84 g/kg) mice. Black arrows indicate neuronal karyopyknosis, chromatolysis and shrinkage of cells. Red arrows indicate a decrease in Nissl bodies. Scale bar, $200 \mu \mathrm{m}$. (B) Percentage of positively stained Nissl cells. Data are presented as the mean \pm standard error ( $\mathrm{n}=3$ /group). ${ }^{* *} \mathrm{P}<0.01$ vs. SAMR1 group; ${ }^{\#} \mathrm{P}<0.05$ and ${ }^{\#} \mathrm{P}<0.01$ vs. SAMP8 group. BSYZ, Bushen-Yizhi formula; SAMP8, senescence-accelerated mouse prone 8; SAMRI, senescence-accelerated mouse resistant 1; DG, dentate gyrus.

oxidative damage in the cortex of SAMP8 mice was attenuated following treatment with BSYZ. It has been reported that PPAR- $\gamma$ agonists may reduce oxidative stress (14). The ameliorative effects of BSYZ on oxidative stress were consistent with the effects of BSYZ on increasing PPAR- $\gamma$ expression in the cortex.

It has previously been reported that PPAR- $\gamma$ overexpression prevents apoptosis by upregulating the anti-apoptotic Bcl-2 family proteins, including Bcl-xL (42). SAMP8 mice demonstrated that with age, there was a significant increase in the relative expression of pancreatic genes involved in inflammation, oxidative stress and apoptosis (43). Therefore, the present study detected neuronal apoptosis in the brains of SAMP8 mice and protein expression of Bcl-xL. The results demonstrated that the brains of SAMP8 mice exhibited histological alterations and reduced $\mathrm{Bcl}-\mathrm{xL}$ expression. Following treatment with BSYZ for 30 days, the number of neuronal apoptotic cells was decreased and the expression levels of Bcl-xL were enhanced. These results suggested that BSYZ may exert an anti-apoptotic effect.
In conclusion, the results of the present study indicated that treatment with BSYZ improved cognitive function in SAMP8 mice, and the underlying molecular mechanism may be associated with anti-inflammatory, antioxidative and anti-apoptotic effects. With these multi-target effects, BSYZ may be a potential drug in treating dementia.

\section{Acknowledgements}

Not applicable.

\section{Funding}

The present study was supported by the National Natural Science Foundation of China (grant no. 81703901), the Doctoral Fund of Education Ministry of China (grant no. 20134425110003), the Guangdong Provincial Major Science and Technology for Special Program of China (grant no. 2012A080202017), the Shandong Province Natural Science Foundation of China (grant no. ZR2016HB56), the 
Foundation of Overseas Distinguished Taishan Scholars of Shandong Province, and the Collaborative Innovation Center for Research and Development of Traditional Chinese Medicine in Mount Tai.

\section{Availability of data and materials}

The datasets used and/or analyzed during the current study are available from the corresponding author on reasonable request.

\section{Authors' contributions}

QW and Y-BC designed the experiments. X-QH, H-PS, S-YC and S-HF performed the experiments and $\mathrm{X}-\mathrm{QH}$ and $\mathrm{H}-\mathrm{PS}$ wrote the manuscript. J-GZ revised the experimental design and manuscript. All authors read and approved the final manuscript.

\section{Ethics approval and consent to participate}

Experimental protocols were approved by the Animal Ethics Committee of Guangzhou University of Chinese Medicine, and experiments were performed in compliance with the Guide for the Care and Use of Laboratory Animals (https:/grants.nih.gov/grants/olaw/guide-for-the-care-and-useof-laboratory-animals.pdf).

\section{Consent for publication}

Not applicable.

\section{Competing interests}

The authors declare that they have no competing interests.

\section{References}

1. Rosano C, Marsland AL and Gianaros PJ: Maintaining brain health by monitoring inflammatory processes: A mechanism to promote successful aging. Aging Dis 3: 16-33, 2012.

2. Carter SF, Schöll M, Almkvist O, Wall A, Engler H, Långström B and Nordberg A: Evidence for astrocytosis in prodromal Alzheimer disease provided by 11C-deuterium-L-deprenyl: A multitracer PET paradigm combining 11C-Pittsburgh compound B and 18F-FDG. J Nucl Med 53: 37-46, 2012.

3. Choo IL, Carter SF, Schöll ML and Nordberg A: Astrocytosis measured by ${ }^{11} \mathrm{C}$-deprenyl PET correlates with decrease in gray matter density in the parahippocampus of prodromal Alzheimer's patients. Eur J Nucl Med Mol Imaging 41: 2120-2126, 2014.

4. Wharton SB, O'Callaghan JP, Savva GM, Nicoll JA, Matthews F, Simpson JE, Forster G, Shaw PJ, Brayne C and Ince PG; MRC Cognitive Function and Ageing Neuropathology Study Group: Population variation in glial fibrillary acidic protein levels in brain ageing: Relationship to Alzheimer-type pathology and dementia. Dement Geriatr Cogn Disord 27 465-473, 2009

5. Simpson JE, Ince PG, Lace G, Forster G, Shaw PJ, Matthews F, Savva G, Brayne C and Wharton SB; MRC Cognitive Function and Ageing Neuropathology Study Group: Astrocyte phenotype in relation to Alzheimer-type pathology in the ageing brain. Neurobiol Aging 31: 578-590, 2010.

6. Medeiros R and LaFerla FM: Astrocytes: Conductors of the Alzheimer disease neuroinflammatory symphony. Exp Neurol 239: 133-138, 2013.
7. Mrak RE and Griffin WS: Interleukin-1, neuroinflammation, and Alzheimer's disease. Neurobiol Aging 22: 903-908, 2001.

8. Ghosh S, Wu MD, Shaftel SS, Kyrkanides S, LaFerla FM, Olschowka JA and O'Banion MK: Sustained interleukin-1 $\beta$ overexpression exacerbates tau pathology despite reduced amyloid burden in an Alzheimer's mouse model. J Neurosci 33: 5053-5064, 2013.

9. Holmes C, Cunningham C, Zotova E, Culliford D and Perry VH: Proinflammatory cytokines, sickness behavior, and Alzheimer disease. Neurology 77: 212-218, 2011.

10. Ho L, Purohit D, Haroutunian V, Luterman JD, Willis F, Naslund J, Buxbaum JD, Mohs RC, Aisen PS and Pasinetti GM: Neuronal cyclooxygenase 2 expression in the hippocampal formation as a function of the clinical progression of Alzheimer disease. Arch Neurol 58: 487-492, 2001.

11. Mollace V, Colasanti M, Muscoli C, Lauro GM, Iannone M, Rotiroti D and Nistico G: The effect of nitric oxide on cytokine-induced release of PGE2 by human cultured astroglial cells. Br J Pharmacol 124: 742-746, 1998.

12. Samy AS and Igwe OJ: Regulation of IL-1 $\beta$-induced cyclooxygenase- 2 expression by interactions of $\mathrm{A} \beta$ peptide, apolipoprotein $\mathrm{E}$ and nitric oxide in human neuroglioma. J Mol Neurosci 47: 533-545, 2012.

13. Ben Haim L, Carrillo-de Sauvage MA, Ceyzériat K and Escartin C: Elusive roles for reactive astrocytes in neurodegenerative diseases. Front Cell Neurosci 9: 278, 2015.

14. Collino M, Aragno M, Mastrocola R, Gallicchio M, Rosa AC, Dianzani C, Danni O, Thiemermann C and Fantozzi R: Modulation of the oxidative stress and inflammatory response by PPAR-gamma agonists in the hippocampus of rats exposed to cerebral ischemia/reperfusion. Eur J Pharmacol 530: 70-80, 2006.

15. Rinaldi P, Polidori MC, Metastasio A, Mariani E, Mattioli P, Cherubini A, Catani M, Cecchetti R, Senin U and Mecocci P: Plasma antioxidants are similarly depleted in mild cognitive impairment and in Alzheimer's disease. Neurobiol Aging 24: 915-919, 2003.

16. Torres LL, Quaglio NB, de Souza GT, Garcia RT, Dati LM, Moreira WL, Loureiro AP, de Souza-Talarico JN, Smid J, Porto CS, et al: Peripheral oxidative stress biomarkers in mild cognitive impairment and Alzheimer's disease. J Alzheimers Dis 26: 59-68, 2011.

17. López N, Tormo C, De Blas I, Llinares I and Alom J: Oxidative stress in Alzheimer's disease and mild cognitive impairment with high sensitivity and specificity. J Alzheimers Dis 33: 823-829, 2013.

18. Yan MH, Wang X and Zhu X: Mitochondrial defects and oxidative stress in Alzheimer disease and Parkinson disease. Free Radic Biol Med 62: 90-101, 2013.

19. Rocha NP, Teixeira AL, Scalzo PL, Barbosa IG, de Sousa MS, Morato IB, Vieira EL, Christo PP, Palotás A and Reis HJ: Plasma levels of soluble tumor necrosis factor receptors are associated with cognitive performance in Parkinson's disease. Mov Disord 29: 527-531, 2014.

20. Lindqvist D, Hall S, Surova Y, Nielsen HM, Janelidze S, Brundin L and Hansson O: Cerebrospinal fluid inflammatory markers in Parkinson's disease-associations with depression, fatigue, and cognitive impairment. Brain Behav Immun 33: 183-189, 2013.

21. Hou XQ, Wu DW, Zhang CX, Yan R, Yang C, Rong CP, Zhang L, Chang X, Su RY, Zhang SJ, et al: Bushen-Yizhi formula ameliorates cognition deficits and attenuates oxidative stressrelated neuronal apoptosis in scopolamine-induced senescence in mice. Int J Mol Med 34: 429-439, 2014.

22. Hou XQ, Zhang L, Yang C, Rong CP, He WQ, Zhang CX, Li S, Su RY, Chang X, Qin JH, et al: Alleviating effects of Bushen-Yizhi formula on ibotenic acid-induced cholinergic impairments in rat. Rejuvenation Res 18: 111-127, 2015.

23. Del Valle J, Bayod S, Camins A, Beas-Zárate C, Velázquez-Zamora DA, González-Burgos I and Pallàs M: Dendritic spine abnormalities in hippocampal CA1 pyramidal neurons underlying memory deficits in the SAMP8 mouse model of Alzheimer's disease. J Alzheimers Dis 32: 233-240, 2012.

24. Chen Y, Wei G, Nie H, Lin Y, Tian H, Liu Y, Yu X, Cheng S, Yan R, Wang Q, et al: $\beta$-Asarone prevents autophagy and synaptic loss by reducing ROCK expression in asenescence-accelerated prone 8 mice. Brain Res 1552: 41-54, 2014.

25. Zhu L, Zhang L, Zhan L, Lu X, Peng J, Liang L, Liu Y, Zheng L, Zhang F and Liu Q: The effects of Zibu Piyin Recipe components on scopolamine-induced learning and memory impairment in the mouse. J Ethnopharmacol 151: 576-582, 2014. 
26. Livak KJ and Schmittgen TD: Analysis of relative gene expression data using real-time quantitative PCR and the 2(-Delta Delta C(T) method. Methods 25: 402-408, 2001.

27. Cheng XR, Zhou WX and Zhang YX: The behavioral, pathological and therapeutic features of the senescence-accelerated mouse prone 8 strain as an Alzheimer's disease animal model. Ageing Res Rev 13: 13-37, 2014.

28. Orejana L, Barros-Miñones L, Jordán J, Puerta E and Aguirre N: Sildenafil ameliorates cognitive deficits and tau pathology in a senescence-accelerated mouse model. Neurobiol Aging 33: 625 e11-e20, 2012.

29. He XL, Zhou WQ, Bi MG and Du GH: Neuroprotective effects of icariin on memory impairment and neurochemical deficits in senescence-accelerated mouse prone 8 (SAMP8) mice. Brain Res 1334: 73-83, 2010.

30. Engelhart MJ,Geerlings MI, Meijer J,Kiliaan A, Ruitenberg A,van Swieten JC, Stijnen T, Hofman A, Witteman JC and Breteler MM: Inflammatory proteins in plasma and the risk of dementia: The rotterdam study. Arch Neurol 61: 668-672, 2004

31. Koyama A, O'Brien J, Weuve J, Blacker D, Metti AL and Yaffe K: The role of peripheral inflammatory markers in dementia and Alzheimer's disease: A meta-analysis. J Gerontol A Biol Sci Med Sci 68: 433-440, 2013

32. Kashon ML, Ross GW, O'Callaghan JP, Miller DB, Petrovitch H, Burchfiel CM, Sharp DS, Markesbery WR, Davis DG, Hardman $\mathrm{J}$, et al: Associations of cortical astrogliosis with cognitive performance and dementia status. J Alzheimers Dis 6: 595-604; discussion 673-681, 2004.

33. Watanabe K, Tonosaki K, Kawase T, Karasawa N, Nagatsu I, Fujita $\mathrm{M}$ and Onozuka M: Evidence for involvement of dysfunctional teeth in the senile process in the hippocampus of SAMP8 mice. Exp Gerontol 36: 283-295, 2001.

34. Fernandez-Gómez FJ, Muñoz-Delgado E, Montenegro MF, Campoy FJ, Vidal CJ and Jordán J: Cholinesterase activity in brain of senescence-accelerated-resistant mouse SAMR1 and its variation in brain of senescence-accelerated-prone mouse SAMP8. J Neurosci Res 88: 155-166, 2010.

35. Furman JL, Sama DM, Gant JC, Beckett TL, Murphy MP, Bachstetter AD, Van Eldik LJ and Norris CM: Targeting astrocytes ameliorates neurologic changes in a mouse model of Alzheimer's disease. J Neurosci 32: 16129-16140, 2012.
36. Carrero I, Gonzalo MR, Martin B, Sanz-Anquela JM, Arévalo-Serrano J and Gonzalo-Ruiz A: Oligomers of $\beta$-amyloid protein (A $\beta 1-42)$ induce the activation of cyclooxygenase-2 in astrocytes via an interaction with interleukin-1 $\beta$, tumour necrosis factor- $\alpha$, and a nuclear factor $\kappa-B$ mechanism in the rat brain. Exp Neurol 236: 215-227, 2012.

37. Eriksson UK, Pedersen NL, Reynolds CA, Hong MG, Prince JA, Gatz M, Dickman PW and Bennet AM: Associations of gene sequence variation and serum levels of C-reactive protein and interleukin-6 with Alzheimer's disease and dementia. J Alzheimers Dis 23: 361-369, 2011.

38. Liu J, Wang LN and Jia JP: Peroxisome proliferator-activated receptor-gamma agonists for Alzheimer's disease and amnestic mild cognitive impairment: A systematic review and meta-analysis. Drugs Aging 32: 57-65, 2015.

39. Pertusa M, Garcia-Matas S, Rodriguez-Farré E, Sanfeliu C and Cristofol R: Astrocytes aged in vitro show a decreased neuroprotective capacity. J Neurochem 101: 794-805, 2007.

40. Padurariu M, Ciobica A, Hritcu L, Stoica B, Bild W and Stefanescu C: Changes of some oxidative stress markers in the serum of patients with mild cognitive impairment and Alzheimer's disease. Neurosci Lett 469: 6-10, 2010.

41. Nakajima A, Aoyama Y, Nguyen TT, Shin EJ, Kim HC, Yamada S, Nakai T, Nagai T, Yokosuka A, Mimaki Y, et al: Nobiletin, a citrus flavonoid, ameliorates cognitive impairment, oxidative burden, and hyperphosphorylation of tau in senescence-accelerated mouse. Behav Brain Res 250: 351-360, 2013.

42. Wu JS, Lin TN and Wu KK: Rosiglitazone and PPAR-gamma overexpression protect mitochondrial membrane potential and prevent apoptosis by upregulating anti-apoptotic Bcl-2 family proteins. J Cell Physiol 220: 58-71, 2009.

43. Cuesta S, Kireev R, Garcia C, Forman K, Escames G, Vara E and Tresguerres JA: Beneficial effect of melatonin treatment on inflammation, apoptosis and oxidative stress on pancreas of a senescence accelerated mice model. Mech Ageing Dev 132: 573-582, 2011.

This work is licensed under a Creative Commons Attribution-NonCommercial-NoDerivatives 4.0 International (CC BY-NC-ND 4.0) License. 